\title{
Histopathological and immunohistochemical approaches for the diagnosis of Pasteurellosis in swine population of Punjab
}

Payal Bhat ${ }^{1}$, Nittin Dev Singh ${ }^{1}$, Geeta Devi Leishangthem², Amninder Kaur ${ }^{1}$, Vishal Mahajan ${ }^{2}$, Harmanjit Singh Banga ${ }^{1}$ and Rajinder Singh Brar ${ }^{1}$

1. Department of Veterinary Pathology, College of Veterinary Science, Guru Angad Dev Veterinary and Animal Sciences University, Ludhiana -141 004, Punjab, India; 2. Animal Disease Research Centre, Guru Angad Dev Veterinary and Animal Sciences University, Ludhiana- 141004 , Punjab, India.

Corresponding author: Nittin Dev Singh, e-mail: drndsingh@gmail.com,

PB: dr.payalbhat@gmail.com,GDL: drgeetapatho@gmail.com, AK: dramninder90@gmail.com, VM: mahajanv17@gmail.com, HSB: bangahs3@yahoo.com, RSB: rsbrar@email.com

Received: 02-03-2016, Accepted: 06-08-2016, Published online: 18-09-2016

doi: 10.14202/vetworld.2016.989-995 How to cite this article: Bhat P, Singh ND, Leishangthem GD, Kaur A, Mahajan V, Banga HS, Brar RS (2016) Histopathological and immunohistochemical approaches for the diagnosis of Pasteurellosis in swine population of Punjab, Veterinary World, 9(9): 989-995.

\begin{abstract}
Aim: Infectious porcine bronchopneumonia, caused by Pasteurella multocida, is a widespread disease of major economic significance. Thus, the aim of the present study was to diagnose swine Pasteurellosis using gross, histopathological, and immunopathological approaches in the swine population of Punjab and to compare the efficacy of immunohistochemical (IHC) techniques with conventional diagnostic techniques.
\end{abstract}

Materials and Methods: A total of 71 adult swine lung samples showing gross pneumonic changes were collected along with the associated lymph nodes to carry out the study. The collected samples were then processed for histopathological and IHC studies.

Results: Out of the total 71 lung samples, 26 samples were found to be suspected for Pasteurellosis as per the microscopic changes observed, and out of these 26 samples, 16 cases were confirmed to be positive for Pasteurellosis by IHC. Varied macroscopic changes noted in lungs were pneumonic patches with consolidation of many lobes, congestion, and focal hemorrhages. Main lesions associated with lymph nodes were its enlargement and hemorrhages. Histologically, the lung showed fibrinous and suppurative bronchopneumonia, multifocal suppuration, thickening of septa with fibrin combined with cellular infiltration and edema. The higher IHC expression of P. multocida was seen in the bronchial epithelium besides in alveolar and bronchial exudate. Moreover, on comparing the histopathological and IHC scores which were calculated on the basis of characteristic microscopic lesions and number of antigen positive cells, respectively, a significant positive correlation $(\mathrm{r}=0.4234)$ was found.

Conclusion: It was concluded that swine population of Punjab is having P. multocida infection. The gross and histopathological lesions can be helpful in the preliminary diagnosis of Pasteurellosis but needs to be supplemented by other immunodiagnostic tests. Moreover, IHC technique proved to be a specific, reliable, precise, and rapid technique to supplement these conventional methods of diagnosis for Pasteurellosis.

Keywords: histopathology, immunohistochemical, Pasteurellosis, scoring.

\section{Introduction}

Swine mortality is an important factor affecting the economic viability and profitability of swine industry. There are several bacterial, viral, parasitic, and managemental diseases of pigs that cause direct financial loss to farmers. Of several diseases, infectious pneumonia(s) has been shown to cause the greatest economic losses in pig houses [1], and it contributes $14 \%$ of the impact on the total disease expenses.

Pig rearing has traditionally been the main occupation of socially backward classes, especially in

Copyright: Bhat, et al. Open Access. This article is distributed under the terms of the Creative Commons Attribution 4.0 International License (http://creativecommons.org/licenses/by/4.0/), which permits unrestricted use, distribution, and reproduction in any medium, provided you give appropriate credit to the original author(s) and the source, provide a link to the Creative Commons license, and indicate if changes were made. The Creative Commons Public Domain Dedication waiver (http://creativecommons.org/ publicdomain/zero/1.0/) applies to the data made available in this article, unless otherwise stated.
Northeastern states of India. It plays an important role for improvement of socioeconomic condition of poor farmers in India and also other developing countries. Moreover, due to rising per capita income, growing urbanization, and unfolding globalization, there is a rapid change in dietary habits of the people and the demand for pork has swiftly increased worldwide in the recent years. Lately, pig farming has gained popularity in Punjab with the introduction of new technologies for rearing and breeding of pigs along with subsidies being provided by central and state government schemes. The estimated profit due to pig farming topped other subsidiary occupations such as dairying, poultry, and sheep rearing; but due to the prevalence of many diseases in swines which go undiagnosed, the poor farmers also suffer huge economic losses. In the most recent decades, the population has declined to approximately 12 million head from a high of 14 million in 2003, as indicated by the $18^{\text {th }}$ Livestock Census of India [2]. Among all, respiratory diseases were 
found to be the fifth most important cause of mortality in crossbred pig in India [3].

Currently, infectious diseases of multifactorial etiology dominate in pigs. Among these, infectious porcine bronchopneumonia is a widespread disease of major economic significance [4]. Mainly, it is characterized by bronchopneumonia [5]. A frequent finding among the infectious agents incriminated with bronchopneumonia in pigs is the Gram-negative bacterium Pasteurella multocida [6]. P. multocida is also one of the causative agents of Porcine Respiratory Disease Complex (PRDC); however, it is rarely considered to be the primary agent but rather constitutes a part of the PRDC [6]. It is believed that P. multocida plays an important role by accentuating lung lesions, but little is known about the mechanism behind it [6]. Lesions associated with $P$. multocida are usually characterized by exudation into bronchi and bronchioles, but necrosis of lung tissue and sepsis may also be commonly observed [7].

Moreover, the status of Pasteurellosis is not known in the swine population of Punjab, and there are no available data regarding the pathology of Pasteurellosis in Punjab, and elimination of infectious agents can be successfully achieved only if the agent in question can be accurately identified. Therefore, the present study was conducted to know the presence of Pasteurellosis in swine population of Punjab, and an attempt was made for early diagnosis of Pasteurellosis in swines using gross and histopathological lesions and then authenticating the results by immunohistochemistry (IHC).

\section{Materials and Methods}

\section{Ethical approval}

The present study was conducted after the approval of the Research Committee and the Institutional Animal Ethics Committee.

\section{Collection and processing of samples}

A total of 71 tissue samples of pneumonic lungs and associated lymph nodes (mediastinal and bronchial) were randomly collected from slaughterhouse/ butcher shops and post-mortem hall of Guru Angad Dev Veterinary and Animal Sciences University (GADVASU), Ludhiana. The relevant tissue samples were fixed in 10\% neutral buffered formalin for histopathology and IHC studies. The tissues were then processed and the $4 \mu$ thick tissue sections were cut out of the paraffin-embedded tissue blocks and stained with hematoxylin and eosin staining as per the protocol of Bancroft and Gamble [8].

IHC

For IHC studies, section(s) were taken on polyL-lysine coated slides and then subjected to a clearing which was followed by rehydration. The antigen retrieval was carried out in citrate buffer using EZ-Retriever ${ }^{\circledR}$ (Biogenex, USA). These slides were then washed in phosphate buffer saline for $20 \mathrm{~min}$.
Serum blocking was done using normal horse serum, and subsequently, non-specific binding and endogenous peroxidase blocking were followed by overnight incubation with polyclonal antibody for P. multocida that was standardized at the dilution of 1:2500. It was then followed by 20 min incubation with secondary antibody (Vector, impress reagent kit; peroxidase universal antimouse/rabbit Ig). Color was developed with substrate diaminobenzidine (vector) and counterstained with Gill's hematoxylin (Merck, Germany) stain. Omission of primary antibodies was used for negative control. Further, IHC scoring was done on the basis of antigen positive cells and classified as mild, moderate, and severe.

\section{Statistical analysis}

The SPSS software was employed to statistically ascertain the relationship between the scoring of histopathological changes in the lungs from affected pigs and the immunohistopathological scoring of the histopathologically positive samples using suitable statistical methods and formulae (mean, standard deviation, and Pearson's correlation) to derive out the significant correlations. This immunohistopathological scoring was done using the scoring scale of 0-3, where five sites in each tissue section were observed under the microscope, and subsequently, the scoring was done by seeing the number of positive cells.

\section{Results and Discussion}

A total of 71 adult swine lung samples along with associated lymph nodes were collected for the study. The lungs which showed gross pneumonic changes were only collected for the study.

\section{Gross}

Main gross lung lesions observed in most of the cases were pneumonic patches in the lung with consolidation of many lobes, congestion, and focal hemorrhages (Figure-1), these observations were in accordance with Harish et al. [9] and Ghosh et al. [10]. Apart from it, patches of emphysematous areas were also noted and frothy exudate was seen oozing out

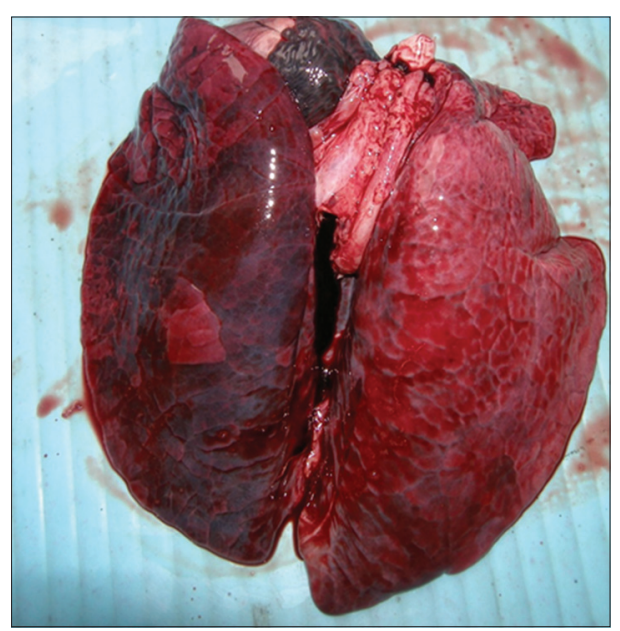

Figure-1: Lung grossly showing diffuse consolidation with hemorrhages in case of Pasteurella multocida. 
after cutting the pneumonic patches of lungs. Beside it, small amount of frothy exudate in trachea and hydrothorax (Figure-2) was also noted as found by Tigga et al. [11] and Harish et al. [9]. Main lesions associated with lymph nodes were its enlargement and hemorrhages, and similar lesions were reported by Ghosh et al. [10].

\section{Histopathology}

Out of 71 samples, $36.62 \%$ (26) cases were found to be showing characteristic histopathological lesions of $P$. multocida and were characterized by moderate fibrinous and suppurative bronchopneumonia (Figure-3), multifocal suppuration, thickening of septa with fibrin combined with cellular infiltration and edema (Figure-4). Alveoli were also infiltrated with fibrinous exudate, erythrocytes, and polymorphonuclear cells (Figure-5) with focal area of necrosis which was surrounded by a zone of fibrous capsule (Figure-6). In addition to it, thickening of pleura and subpleural hemorrhage(s) was also noted. Similar histological lesions in lungs were observed by Tigga et al. [11]. The lesions such as bronchioles filled with necrotic exudates containing inflammatory cells and multifocal hemorrhages in the interstitial spaces

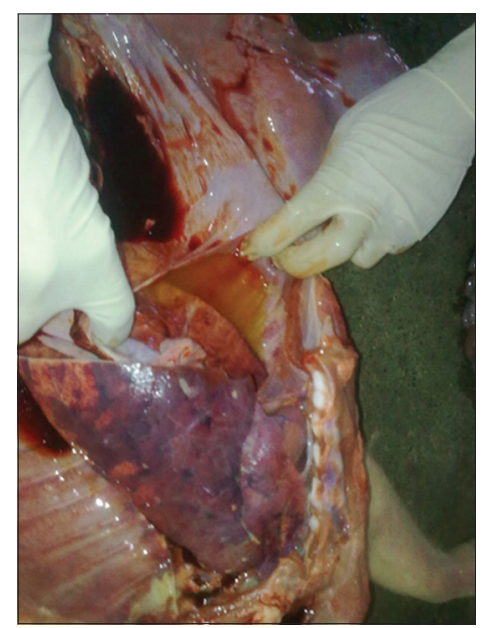

Figure 2: Diffuse lung consolidation with hydrothorax.

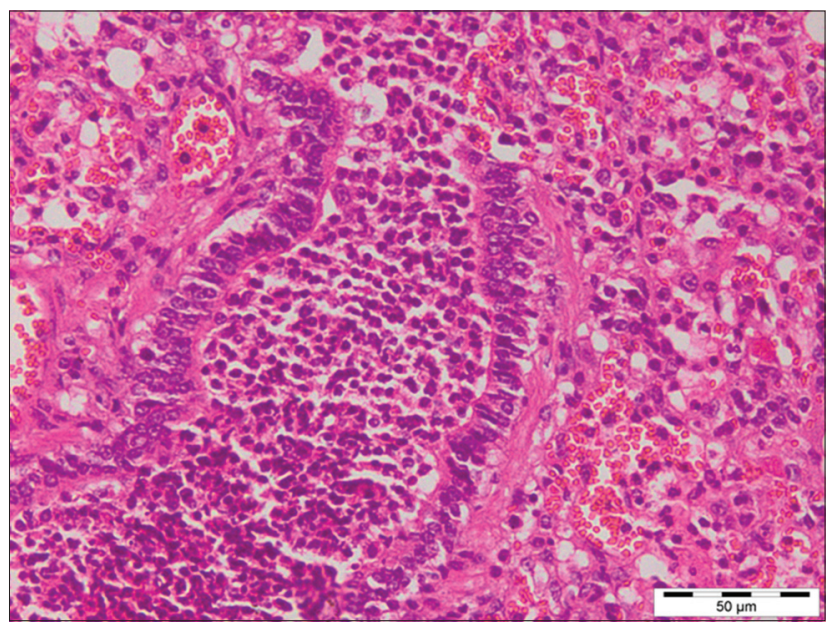

Figure-3: Severe suppurative bronchopneumonia in case of Pasteurellosis in pig ( $\mathrm{H}$ and $\mathrm{E}, 400 \times)$.
(Figure-7) were in accordance with Harish et al. [9]. In some cases, chronic active bronchopneumonia represented by exudation in the alveoli and bronchiole with different cell types, including neutrophils or a mixed cell population consisting of lymphocytes, neutrophils, and macrophages were also found. Similar histopathological lesions were reported by Ono et al. [12] and Pors et al. [13], along with it fibrous tissue proliferation was also present. Lesions observed in some cases were similar to that reported by Cardoso et al. [14], i.e. necrotizing bronchopneumonia associated with bronchial epithelium degeneration, hemorrhage, congestion, edema (Figure-8), fibrinous pleuritis, and emphysema in area adjacent to bronchopneumonia along with these necrotic areas with bacterial colonies were also seen (Figures-9 and 10). Main lesions associated with lymph nodes were found similar to that reported by Cardoso et al. [14] and Tigga et al. [11] that included hemorrhage, congestion, and lymphoid depletion (Figure-11).

According to an earlier study by Ciprian et al. [15], it was reported that P. multocida behaves

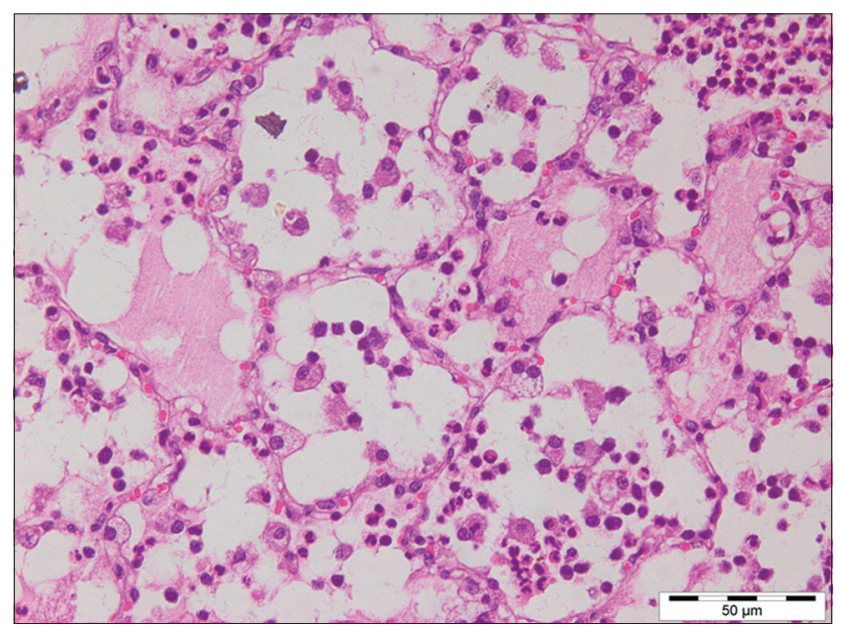

Figure-4: Thickening of alveolar septa with fibrin combined with cellular infiltration and edema in case of Pasteurellosis ( $H$ and $E, 400 \times)$.

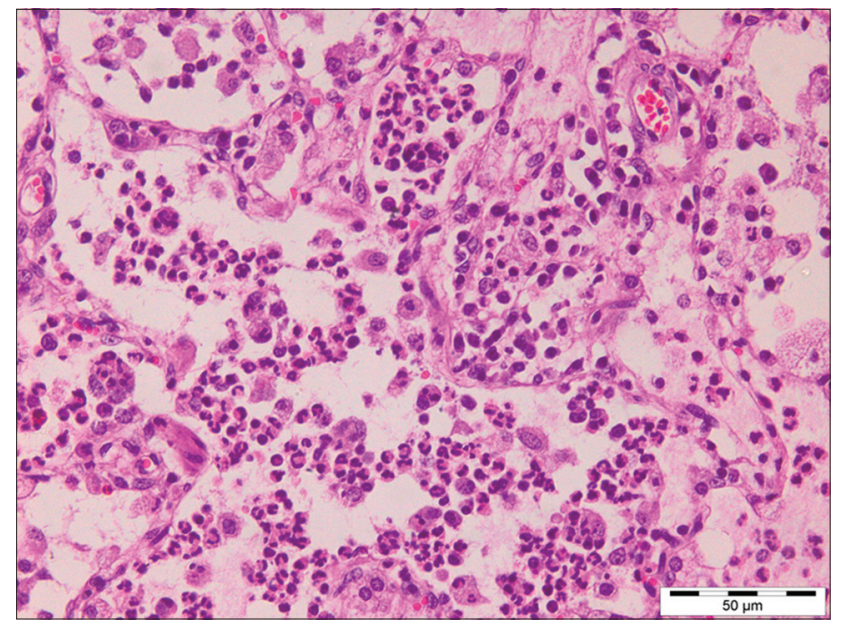

Figure-5: Alveoli filled with fibrinous exudate, erythrocytes, and polymorphonuclear cells in case of Pasteurellosis ( $\mathrm{H}$ and $\mathrm{E}, 400 \times)$. 


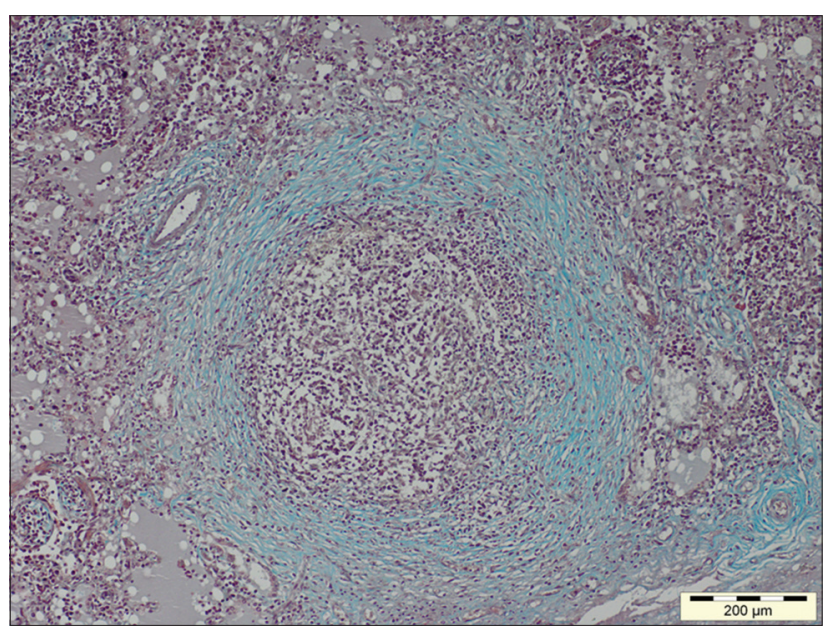

Figure-6: Focal area of necrosis surrounded by fibrous capsule in case of Pasteurellosis (Masson's trichrome, $100 \times)$.

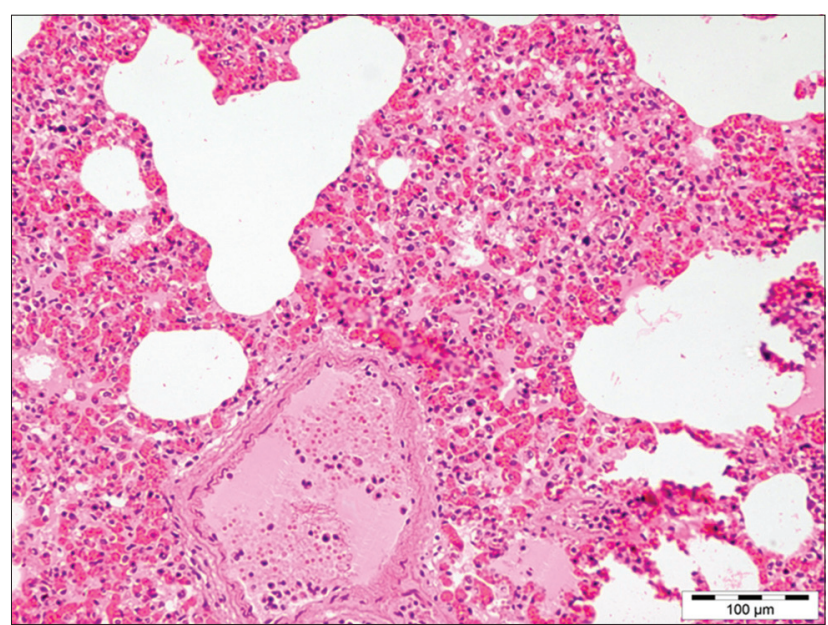

Figure-7: Diffuse hemorrhage in interstitial space of lung in case of Pasteurellosis ( $\mathrm{H}$ and $\mathrm{E}, 200 \times$ ).

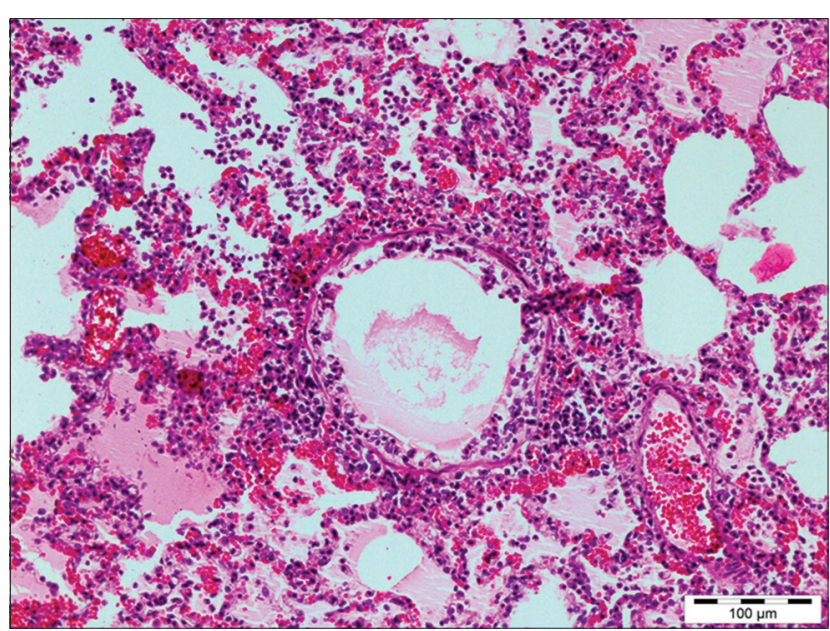

Figure-8: Bronchial epithelium degeneration, congestion, hemorrhage, and edema in lungs of pigs affected with Pasteurellosis ( $\mathrm{H}$ and $\mathrm{E}, 200 \times$ ).

as a secondary infectious agent along with main pathogens (viz., Mycoplasma hyopneumoniae, Actinobacillus pleuropneumoniae, and Bordetella bronchiseptica) causing pneumonia. P. multocida

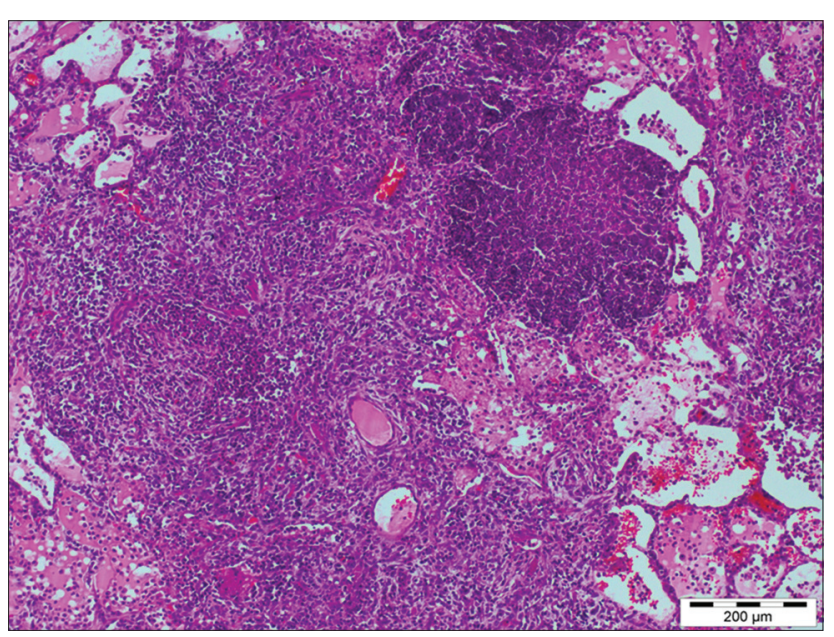

Figure-9: Multifocal necrotic areas in lung of pigs infected with Pasteurella multocida (H and E, 100x).

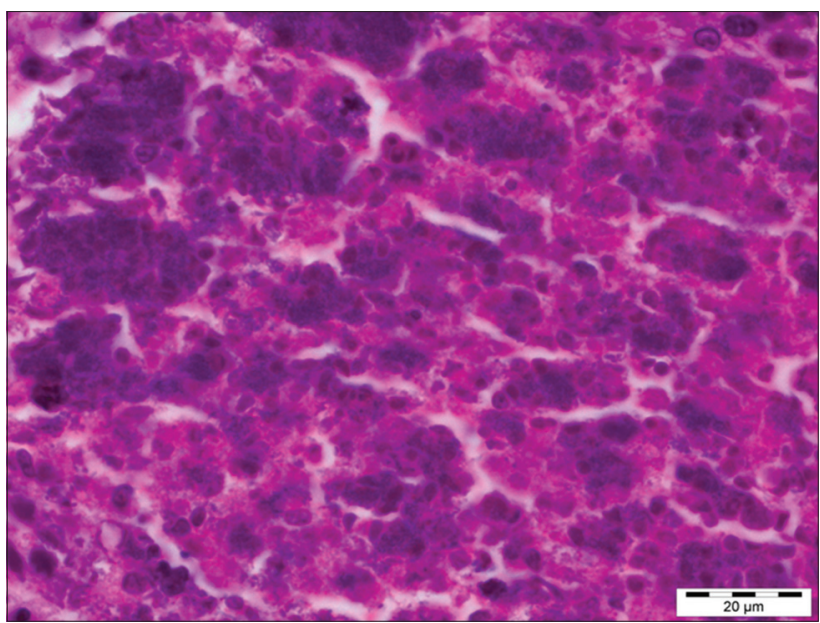

Figure-10: Necrotic areas showing the presence of bacterial colonies ( $\mathrm{H}$ and $\mathrm{E}, 1000 \times)$.

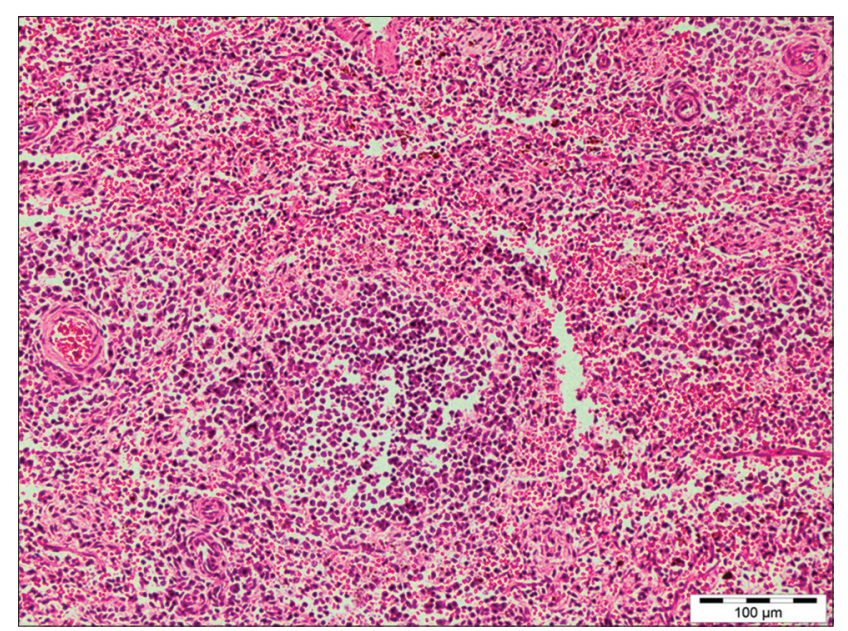

Figure-11: Lymph node showing diffuse hemorrhage and congestion in case of Pasteurellosis ( $H$ and $E, 200 \times)$.

acts synergistically with other pathogens to increase respiratory lesions $[6,16]$. P. multocida is a normal commensal of upper respiratory tract of animals, and under any stress condition or infection with other agents, P. multocida proliferates and leads to occurrence of associated disease condition, thus with 
bronchopneumonia in pigs it is usually considered to be a secondary pathogen which is dependent on co-infection or immunosuppression of the host [17]. More neutrophil population in the present study is due to the fact that clearance of $P$. multocida from porcine lung depends on the presence of neutrophils as reported by Muller and Kohler [18]. Macrophage infiltration was also seen as neutrophils together with macrophages mediate phagocytosis and cytokine production [19].

The scoring of the various Pasteurellosis lesions in lung was done as shown in Table-1. As per the statistical analysis, it was observed that histopathological lesions associated with P. multocida showed mild degeneration and necrosis along with moderate changes such as inflammatory cell infiltration, hemorrhage, and bronchopneumonia.

\section{Immunohistopathology}

Around 26 cases that were suspected for Pasteurellosis by histopathological observations were further processed for detection of $P$. multocida antigen. Out of 26, a positive reaction was found in $61.54 \%(16 / 26)$ cases.

The affected lungs revealed antigen in bronchial epithelium (Figure-12), alveolar, and bronchial content having neutrophil and macrophages (Figures-13 and 14). These findings can be related to the findings of Ozyildiz et al. [20]. Mild positive reaction was also seen in lymphocytes in lymph nodes (Figure-15). The findings in the present study supported that the disease spread by the endobronchial way. In addition to it, the reaction in neutrophils was due to the fact that clearance of $P$. multocida from porcine lung depends on the presence of neutrophils. These findings were in accordance with the earlier study by Muller and Kohler [18].

\section{Statistical analysis}

To statistically ascertain the relationship between the histopathological changes in the lung from affected pigs and the immunohistopathological scores, the immunohistopathological scoring of 16 out of 26 histopathologically positive samples was done using the scoring scale of $0-3$.

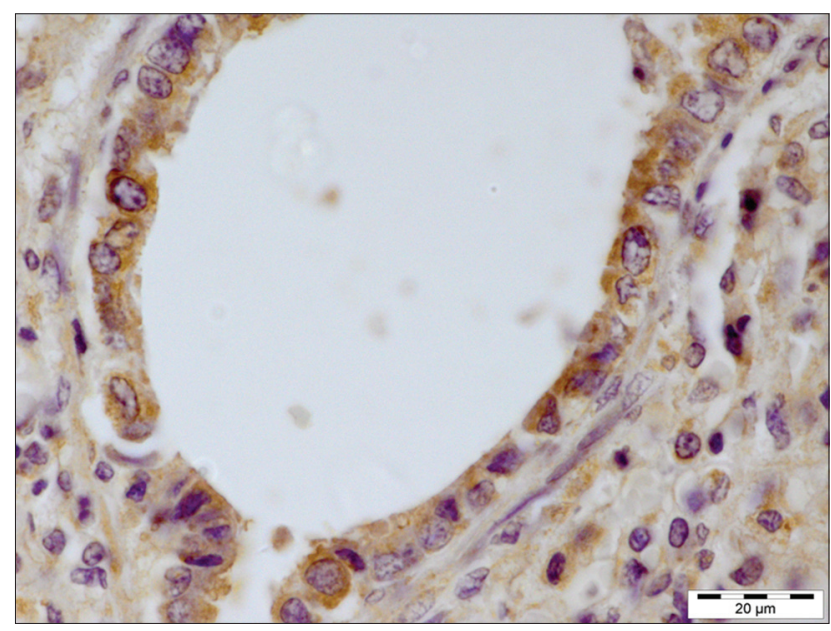

Figure-12: Presence of Pasteurella multocida antigen throughout the bronchial epithelium (immunohistochemical, $1000 \times)$.

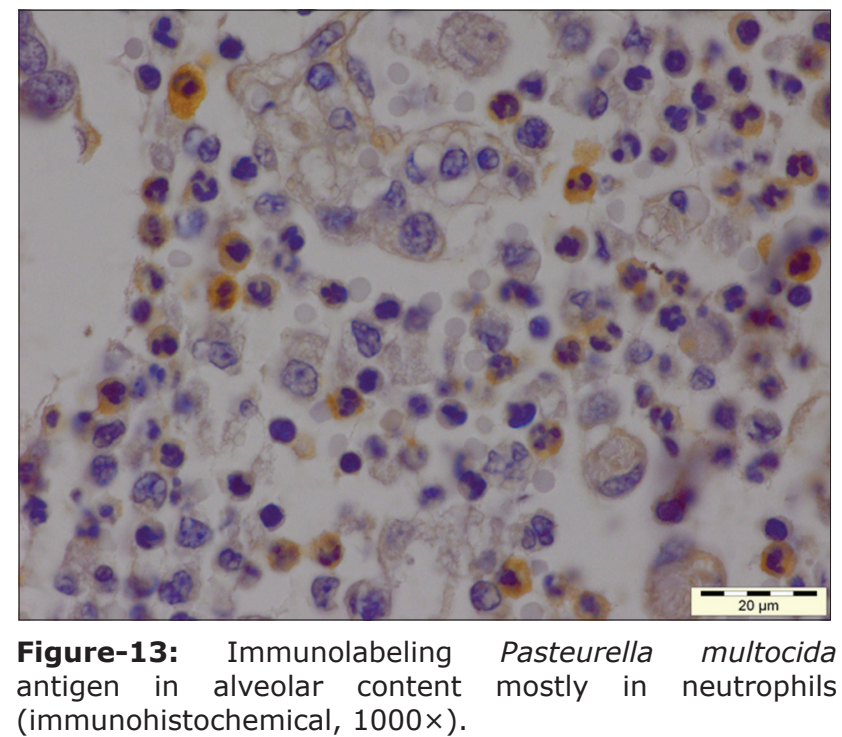

Table-1: Histopathological scoring of lung lesions in case of Pasteurellosis.

\begin{tabular}{lccc}
\hline Slide No. & $\begin{array}{c}\text { Inflammatory cells } \\
\text { infiltration and hemorrhage }\end{array}$ & $\begin{array}{c}\text { Degeneration } \\
\text { and } \text { necrosis }\end{array}$ & Bronchopneumonia \\
\hline PB-1 & $2.8 \pm 0.4$ & $1.4 \pm 0.49$ & $2.8 \pm 0.4$ \\
PB-2 & $2.6 \pm 0.49$ & $1.4 \pm 0.49$ & $1.4 \pm 0.49$ \\
PB-3 & $1.4 \pm 0.49$ & $2 \pm 0.63$ & $1.2 \pm 0.4$ \\
PB-4 & $3 \pm 0$ & $2.2 \pm 0.75$ & $1.4 \pm 0.49$ \\
PB-5 & $1.6 \pm 0.49$ & $1 \pm 0$ & $1.4 \pm 0.49$ \\
PB-6 & $2.8 \pm 0.4$ & $1.8 \pm 0.75$ & $2.8 \pm 0.4$ \\
PB-8 & $2.4 \pm 0.8$ & $1 \pm 0$ & $2 \pm 0.63$ \\
PB-10 & $3 \pm 0$ & $2.8 \pm 0.4$ & $3 \pm 0$ \\
PB-18 & $2.2 \pm 0.75$ & $0.2 \pm 0.4$ & $0.2 \pm 0.4$ \\
PB-29 & $2.4 \pm 0.49$ & $1.8 \pm 0.75$ & $2.2 \pm 0.4$ \\
PB-34 & $1.2 \pm 0.4$ & $0.2 \pm 0.4$ & $0.2 \pm 0.4$ \\
PB-40 & $1.4 \pm 0.49$ & $0.6 \pm 0.49$ & $0.6 \pm 0.49$ \\
PB-50 & $1 \pm 0$ & $0.4 \pm 0.49$ & $0 \pm 0$ \\
PB-56 & $2.6 \pm 0.49$ & $1.6 \pm 0.8$ & 0.49 \\
PB-60 & $0.6 \pm 0.49$ & $0 \pm 0$ & $0.2 \pm 0.4$ \\
PB-70 & $1.8 \pm 0.75$ & $1 \pm 0$ & $2.6 \pm 0.49$ \\
Mean lesion score & $2.0 \pm 0.74$ & $1.2 \pm 0.78$ & $1.6 \pm 1.03$ \\
\hline
\end{tabular}


Table-2: Overall histopathological scoring and the IHC scoring of lung lesions in Pasteurellosis.

\begin{tabular}{lccccc}
\hline Case No. & $\begin{array}{c}\text { Inflammatory cells } \\
\text { infiltration and hemorrhage } \\
\text { (mean } \pm \text { SD) }\end{array}$ & $\begin{array}{c}\text { Degeneration } \\
\text { and necrosis } \\
(\mathbf{m e a n} \pm \mathbf{S D})\end{array}$ & $\begin{array}{c}\text { Bronchopneumonia } \\
\text { (mean } \mathbf{m} \text { ) }\end{array}$ & $\begin{array}{c}\text { Overall } \\
\text { histopathological } \\
\text { score }\end{array}$ & $\begin{array}{c}\text { IHC score } \\
\text { (mean } \pm \text { SD) }\end{array}$ \\
\hline PB-1 & $2.8 \pm 0.4$ & $1.4 \pm 0.49$ & $2.8 \pm 0.4$ & $2.33 \pm 0.66$ & $2.2 \pm 0.75$ \\
PB-2 & $2.6 \pm 0.49$ & $1.4 \pm 0.49$ & $1.4 \pm 0.49$ & $1.8 \pm 0.56$ & $2 \pm 0$ \\
PB-3 & $1.4 \pm 0.49$ & $2 \pm 0.63$ & $1.2 \pm 0.4$ & $1.53 \pm 0.33$ & $1.4 \pm 0.8$ \\
PB-4 & $3 \pm 0$ & $2.2 \pm 0.75$ & $1.4 \pm 0.49$ & $2.2 \pm 0.65$ & $0.6 \pm 0.8$ \\
PB-5 & $1.6 \pm 0.49$ & $1 \pm 0$ & $1.4 \pm 0.49$ & $1.33 \pm 0.25$ & $1.4 \pm 0.8$ \\
PB-6 & $2.8 \pm 0.4$ & $1.8 \pm 0.75$ & $2.8 \pm 0.4$ & $2.47 \pm 0.47$ & $1.8 \pm 0.98$ \\
PB-8 & $2.4 \pm 0.8$ & $1 \pm 0$ & $2 \pm 0.63$ & $1.8 \pm 0.59$ & $2 \pm 0.63$ \\
PB-10 & $3 \pm 0$ & $2.8 \pm 0.4$ & $3 \pm 0$ & $2.94 \pm 0.09$ & $1.2 \pm 0.75$ \\
PB-18 & $2.2 \pm 0.75$ & $0.2 \pm 0.4$ & $0.2 \pm 0.4$ & $0.87 \pm 0.94$ & $1.2 \pm 0.75$ \\
PB-29 & $2.4 \pm 0.49$ & $1.8 \pm 0.75$ & $2.2 \pm 0.4$ & $2.13 \pm 0.25$ & $1.8 \pm 0.75$ \\
PB-34 & $1.2 \pm 0.4$ & $0.2 \pm 0.4$ & $0.2 \pm 0.4$ & $0.53 \pm 0.47$ & $0.8 \pm 0.4$ \\
PB-40 & $1.4 \pm 0.49$ & $0.6 \pm 0.49$ & $0.6 \pm 0.49$ & $0.87 \pm 0.37$ & $0.4 \pm 0.49$ \\
PB-50 & $1 \pm 0$ & $1.6 \pm 0.8$ & $2.6 \pm 0.49$ & $0.47 \pm 0.41$ & $1.4 \pm 1.02$ \\
PB-56 & $2.6 \pm 0.49$ & 0.49 & $0.2 \pm 0.4$ & $2.27 \pm 0.47$ & $1 \pm 0.89$ \\
PB-60 & $0.6 \pm 0.49$ & $1 \pm 0$ & $2.6 \pm 0.49$ & $0.27 \pm 0.25$ & $0.4 \pm 0.49$ \\
PB-70 & $1.8 \pm 0.75$ & & & $1.8 \pm 0.65$ & $0.6 \pm 0.49$ \\
\hline
\end{tabular}

IHC: Immunohistochemical, SD: Standard deviation

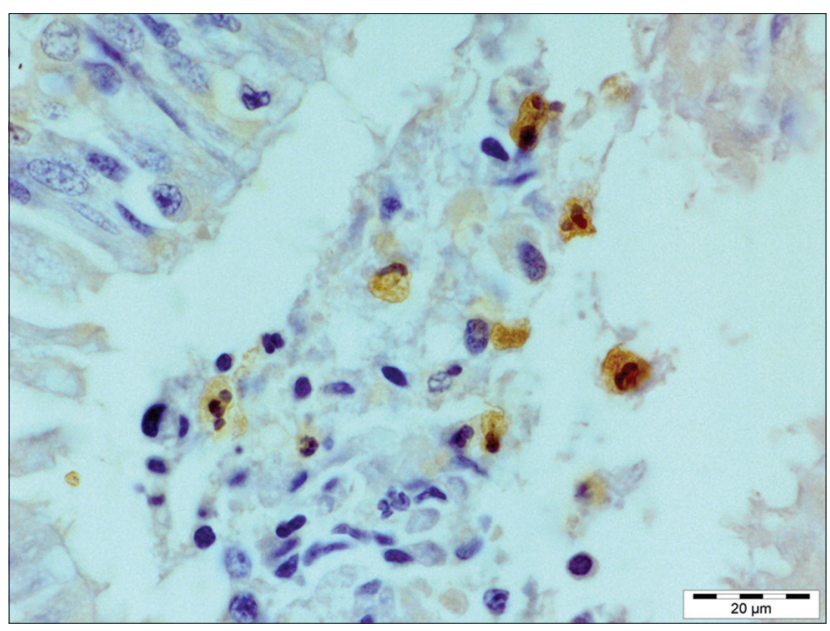

Figure-14: Immunolabeling for Pasteurella multocida antigen in bronchial content (immunohistochemical, $1000 \times)$.

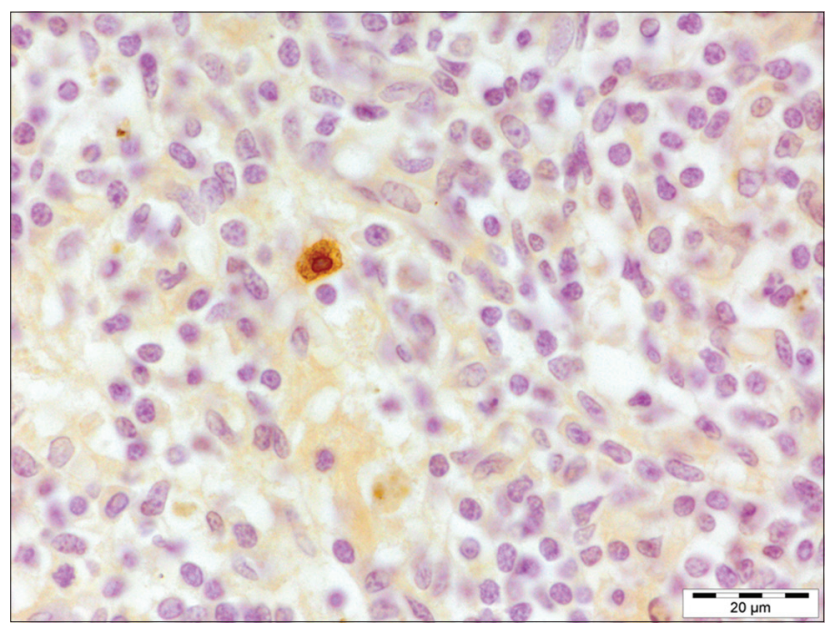

Figure-15: Mild positive reaction for Pasteurella multocida antigen seen in lymphocytes in lymph node (immunohistochemical, 1000x).

For a statistical comparison to be drawn, the mean and the standard deviation of the respective

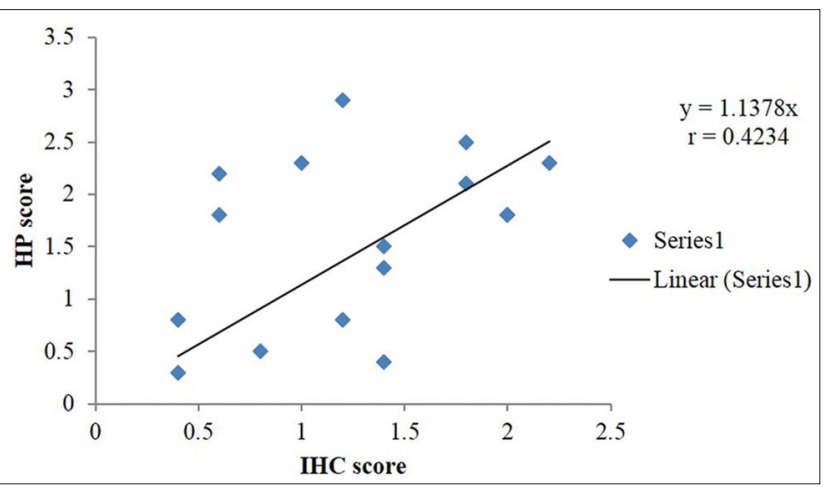

Figure-16: Correlation between histopathology (HP) score and immunohistochemistry (IHC) score in Pasteurellosis (Graph).

histopathological changes were also calculated as shown in Table-2. This mean represented the overall damage to the histoarchitecture, which was then compared with the IHC scoring of the respective cases using the SPSS software (SPSS for Windows version 16 INC, Chicago, Illinois). The correlation coefficient between the mean histopathological scoring and the IHC scoring was also found to be positive, $\mathrm{r}=0.4234$ for the respective cases, which proves the reliability on IHC for the positive cases. Further, it can also be represented graphically, as depicted in Figure-16, where both of the curves follow a similar trend.

\section{Conclusion}

It was concluded that IHC staining is a precise, specific, rapid, and reliable method to demonstrate the Pasteurella antigen in the lung tissues of Pasteurella infected pig. Thus, IHC along with other conventional methods as gross and histopathological examination can be used for diagnosis of Pasteurellosis, i.e., an important respiratory disease of swine. Moreover, it has been reported for the first time that Pasteurellosis is one of the main respiratory diseases prevalent in swine population of Punjab. 


\section{Authors' Contributions}

NDS and PB initiated research concept and design, collection, and analysis of data was compiled by PB, HSB, GDL, VM, and AK. The interpretation of HP was done by NDS and PB. Slide's photography was done by PB and NDS. NDS, HSB, and RSB critically reviewed the article, whereas the final approval of the article was done by PB, NDS, HSB, and RSB. All authors read and approved the final manuscript.

\section{Acknowledgments}

The authors are thankful to Dean Post Graduate Studies, GADVASU and Professor-cum-Head, Department of Veterinary Pathology, GADVASU, Ludhiana, for providing necessary facilities and funds to carry out the research work.

\section{Competing Interests} interests.

The authors declare that they have no competing

\section{References}

1. Christensen, G. and Mousing, J. (1992) Respiratory system. In: Leman, A.D., et al., editors. Diseases of Swine. $7^{\text {th }}$ ed. Iowa State University Press, Ames, Iowa, USA. p138-162.

2. Department of Animal Husbandry, Dairying \& Fisheries 2011. Annual Report 2011-12. Department of Animal Husbandry, Dairying \& Fisheries, Ministry of Agriculture, Government of India, New Delhi.

3. Mondal, S.K., De, U.K., Das, G.K., Powde, A.M. and Verma, A.K. (2012) Pattern of mortality of crossbred pigs in an organized swine production farm. Livest. Sci., 3: 37-44.

4. Sorensen, V., Jorsal, S.E. and Mousing, J. (2006) Diseases of the respiratory system. Diseases of Swine. $9^{\text {th }}$ ed. Iowa State University Press, Ames, Iowa. p149-177.

5. Christensen, G. and Enoe, C. (1999) The prevalence of pneumonia, pleuritis, pericarditis and liver 308 spots in Danish slaugther pigs in 1998, including comparation with 1994. Dan. Vet., 82: 1-12.

6. Hansen, M.S., Pors, S.E., Jensen, H.E., Hansen, V.B., Bisgaard, M., Flachs, E.M. and Nielsen, O.L. (2010) An investigation of the pathology and pathogens associated with porcine respiratory disease 324 complex in Denmark. J. Comp. Pathol., 143: 120-131.

7. Cameron, R.D., Oboyle, D., Frost, A.J., Gordon, A.N. and Fegan, N. (1996) An outbreak of haemorrhagic septicaemia associated with Pasteurella multocida subsp gallicida in large pig herd. Aust. Vet. J., 73: 27-29.

8. Bancroft, J.D. and Gamble, M. (2002) Theory and Practice of Histological Techniques. $5^{\text {th }}$ ed. Churchill Livingstone Publisher, Edinburgh. p172-75.

9. Harish, B.R., Chandranaik, B.M., Venkatesh, M.D., Renukaprasad, C., Jayakumar, S.R. and Krishnapp, G. (2005) An outbreak of swine Pasteurellosis and its pathology. Indian J. Vet. Pathol., 29(2): 129-130.

10. Ghosh, R.C., Hirpurkar, S.D. and Mondal, M. (2011) An outbreak of swine Pasteurellosis in Chhattisgarh. Indian $J$. Vet. Pathol., 35(1): 87-88

11. Tigga, M., Ghosh, R.C., Malik, P., Choudhary, B.K., Tigga, P. and Nagar, D.K. (2014) Isolation, characterization, antibiogram and pathology of isolated from pigs. Vet. World, 7(5): 363-368

12. Ono, M., Okada, M., Namimatsu, T., Fujii, S., Mukai, T. and Sakano, T. (2003) Septicaemia and arthritis in pigs experimentally infected with Pasteurella multocida capsular serotype A. J. Comp. Pathol., 129(4): 251-8.

13. Pors, S.E., Hansen, M.S., Bisgaard, M., Jensen, H.E. and Iburg, T.M. (2013) Immunohistochemical study of porcine lung lesions associated with Pasteurella multocida. Vet. J., 197: 483-488.

14. Cardoso, T.F., Laguna, G.J., Callejo, M., Vela, A.I., Carrasco, L., Fernandez, G.J. F., Maldonado, A. and Luque, I. (2013) Septicaemic Pasteurellosis in free-range pigs associated with an unusual biovar 13 of Pasteurella multocida. Vet. Microbiol., 167(3-4): 690-694.

15. Ciprian, A., Pijoan, C., Cruz, T., Camacho, J., Tortora, J., Colmenares, G., Lopez-Revilla, R. and Garza, M.D. (1988) Mycoplasma hyopneumoniae increases the susceptibility of pigs to experimental Pasteurella multocida. Can. J. Vet. Res., 52: 434-438.

16. Fablet, C., Marois, C., Kuntzsimon, G., Rose, N., Dorenlor, V., Eono, F., Eveno, E., Jolly, J.P., Ledevendec, L., Tocqueville, V., Queguiner, S., Gorin, S., Kobisch, M. and Madec, F. (2011) Longitudinal study of respiratory infection patterns of breeding sows in five farrow-to-finish herds. Vet. Microbiol., 147(3-4): 329-339.

17. Ross, R.F. (2006) Pasteurella multocida and its role in porcine pneumonia. Anim. Health Res. Rev., 7: 13-29.

18. Muller, G. and Kohler, H. (1997) Experimental affecting of pulmonary clearance of Pasteurella multocida induced pneumonia in swine. Berl. Munch. Tierarztl Wochenschr, 110: 378-380.

19. Thacker, E.L. (2006) Mycoplasmal Disease, Diseases of Swine. $9^{\text {th }}$ ed. Iowa State University Press, Ames. p701-717.

20. Ozyildiz, Z., Tel, O.Y., Yilmaz, R., Ozsoy, S.Y. and Keskin, O. (2013) Pathological and microbiological investigations of pneumonic pasteurellosis in sheep. J. Fac Vet Med Univ Kafkas., 19(1): 103-108. 